\title{
Health-Related Quality of Life During Routine Treatment with the SQ-Standardised Grass Allergy Immunotherapy Tablet: A Non-Interventional Observational Study
}

\author{
Andreas Horn ${ }^{1} \cdot$ Herbert Zeuner $^{1} \cdot$ Hendrik Wolf $^{2} \cdot$ Jörg Schnitker $^{3}$. \\ Eike Wüstenberg ${ }^{2,4} \cdot$ GRAZAX LQ-study group
}

Published online: 15 March 2016

(c) The Author(s) 2016. This article is published with open access at Springerlink.com

\begin{abstract}
Background and Objective Allergy immunotherapy (AIT) with the $\mathrm{SQ}^{\circledR}$ grass sublingual immunotherapy (SLIT)-tablet has been shown to be efficacious, well-tolerated and to improve disease-specific health-related quality of life (HRQoL) in controlled clinical trials. The aim of our study was to investigate HRQoL in patients with allergic rhinoconjunctivitis routinely treated with the SLITtablet and taking symptomatic medication as needed compared with patients treated only with symptomatic medication.

Methods In a non-interventional, open-label study, patients treated with the SLIT-tablet were observed for about 12 months compared with patients only symptomatically treated. Patients assessed their HRQoL with the 12-Item Short Form Health Survey (SF-12) and the Rhinitis Quality of Life Questionnaire (RQLQ) in the grass pollen seasons (GPS) at baseline (GPS1, HRQoL1),
\end{abstract}

Data of this article were published in abstract form in Horn et al. [23] and Wolf et al. [24].

Hendrik Wolf

hendrik.wolf@alk.net

HNO Praxis am Neckar, 69120 Heidelberg, Germany

2 ALK-Abelló Arzneimittel GmbH, Clinical Development/ Medical Department, Griegstrasse 75, Haus 25, 22763 Hamburg, Germany

3 Institut für angewandte Statistik Dr. Jörg Schnitker GmbH, 33647, Bielefeld, Germany

4 Clinic for Otolaryngology, Universitätsklinikum Carl Gustav Carus, 01307 Dresden, Germany after GPS1 (HRQoL2) and in the following GPS (GPS2, HRQoL3). Tolerability, compliance, symptoms and medication use were assessed in the SLIT-tablet group by the physician.

Results Overall, data were analysed in 576 patients. Mean differences $( \pm \mathrm{SD})$ in overall scores for HRQoL3 versus HRQoL1 (186 patients) of SF-12 were $+11.4 \pm 16.8$ (SLIT-tablet) and $-3.4 \pm 15.7$ (symptomatic medication), $(p<0.0001)$, and of RQLQ $-1.31 \pm 1.07$ and $+0.10 \pm 0.74(p<0.001)$, and for HRQoL3 versus HRQoL2 (238 patients) of SF-12 $-1.6 \pm 15.3$ and $-10.0 \pm 14.1 \quad(p=0.0003)$, and of RQLQ $+0.22 \pm 1.29$ and $+1.24 \pm 1.30 \quad(p<0.0001)$. Tolerability and adherence for the SLIT-tablet were comparable with data of other non-interventional studies.

Conclusions Routine treatment with the SQ ${ }^{\circledR}$ grass SLITtablet resulted in clear improvements in disease-specific and general quality of life, while no improvements were observed in patients treated only symptomatically.

\section{Key Points}

General (SF-12) and disease-specific (RQLQ) health-related quality of life scales were observed not to improve during the grass pollen season in patients with allergic rhinoconjunctivitis treated only with symptomatic medication in a real-life setting.

Clear improvements in health-related quality of life scales were observed in patients treated with the $\mathrm{SQ}^{\circledR}$ grass sublingual allergy immunotherapy tablet and symptomatic medication as needed compared with the grass pollen season before start of treatment. 


\section{Introduction}

Allergic rhinoconjunctivitis is associated with impairments in the way patients function in day-to-day life and may significantly limit the health-related quality of life (HRQoL) of the patient as well as affecting school learning, performance and work productivity [1].

HRQoL includes a large set of physical and psychological characteristics assessing problems in the social context of a patient's lifestyle. In allergic rhinoconjunctivitis, two types of HRQoL measures-generic and disease-specific - are used $[2,3]$.The $\mathrm{SQ}^{\circledR}$ grass sublingual immunotherapy (SLIT)-tablet, developed for treatment of grass pollen-induced rhinoconjunctivitis was launched in Germany in November 2006 after gaining marketing authorisation in several European countries. The $\mathrm{SQ}^{\circledR}$ grass SLIT-tablet has been developed according to one of the largest clinical development programmes for a product of allergy immunotherapy (AIT). More than 5600 patients have been involved in randomised controlled clinical trials (RCTs) performed in Europe and USA, which collectively have demonstrated clinical efficacy and a favourable safety profile in adults, adolescents and children [4-17]. Diseasespecific HRQoL using the Rhinoconjunctivitis Quality of Life Questionnaire (RQLQ) [3] was also measured in the large placebo-controlled RCTs with the $\mathrm{SQ}^{\circledR}$ grass SLITtablet. The trials have shown significant improvements in the HRQoL in patients treated with the $\mathrm{SQ}^{\circledR}$ grass SLITtablet as compared to placebo [12, 14, 18].

As the patients' perspective on improvements of disease-specific and everyday HRQoL is an important parameter to assess the benefits of a therapeutic intervention, the objective of our study was to explore the general and disease-specific HRQoL during routine treatment with the $\mathrm{SQ}^{\circledR}$ grass SLIT-tablet in the real-life setting. The HRQoL for the SQ ${ }^{\circledR}$ grass SLIT-tablet was compared to the HRQoL obtained for patients treated with symptomatic medication without AIT.

\section{Methods}

\subsection{Study Design}

The study was designed as a multicentre, open, uncontrolled and observational study according to non-interventional post-marketing surveillance studies mentioned in the German drug law analysed by epidemiological methods after marketing authorisation. Study period was between November 2006 and March 2009. Patients who contacted their doctor because of allergic rhinoconjunctivitis during the grass pollen season (GPS) before starting AIT in 2007
(GPS1) and who were potentially eligible for treatment with the $\mathrm{SQ}^{\circledR}$ grass SLIT-tablet $\left(\right.$ GRAZAX $^{\circledR}$ Phleum pratense 75,000 SQ-T/2,800 BAU, ALK, Hørsholm, Denmark) were asked to assess their HRQoL in GPS1 (HRQoL1) and to return after GPS1 either to start AIT and take symptomatic medication as needed or stay only with symptomatic medication (nasal, topical medication, eye drops/oral antihistamines/oral corticosteroids/ $\beta$-agonists/ bronchially applied corticosteroids/other to be specified) without AIT for assessment of their HRQOL outside the grass pollen season (HRQoL2). All patients were asked to return within or shortly after the following GPS (GPS2) for assessment of their HRQoL (HRQoL3). The $\mathrm{SQ}^{\circledR}$ grass SLIT-tablet group in this study consisted of all patients who returned after GPS1 and started treatment with the $\mathrm{SQ}^{\circledR}$ grass SLIT-tablet (a maximum of four patients per site). The control group in a first step consisted of 'all other patients' included in the study. For comparison of the HRQoL data between the $\mathrm{SQ}^{\circledR}$ grass SLIT-tablet group and the symptomatic medication control group without AIT the patients who: 1) returned after GPS1 to start treatment with the $\mathrm{SQ}^{\circledR}$ grass SLIT-tablet but did not participate in the study, 2) returned after GPS1 to start another AIT and 3) did not return after the screening visit, were excluded from the control group. Furthermore, patients with HRQoL data that were not suitable for a comparison of HRQoL3 versus HRQoL1 were excluded. Patients who had their first visit after GPS1 were evaluated with respect to changes in HRQoL scores HRQoL3 (in GPS2) versus HRQoL2 (after GPS1) while patients who had only an off-season visit after GPS2 were not evaluated with respect to HRQoL.

Treatment with the $\mathrm{SQ}^{\circledR}$ grass SLIT-tablet was started after GPS1 and continued for about 12 months until the end of GPS2 (Fig. 1).

Sites were distributed all over Germany to minimize a potential investigator bias. Physicians were asked to include patients in a consecutive order dependent on the patient's willingness to participate in the study to reduce a potential selection bias.

\subsection{Ethics and Data Protection}

According to German drug law, non-interventional postmarketing studies are notified to the authorities. If only data on treatment as part of the routine medical practice are recorded, these studies are not subject to approval by an independent ethics committee. Patients were asked for their consent to participate in the study. For recording and evaluation of data patients were assigned a three-digit patient number. Direct identification of the patients was restricted to the physician's offices participating in the study. 


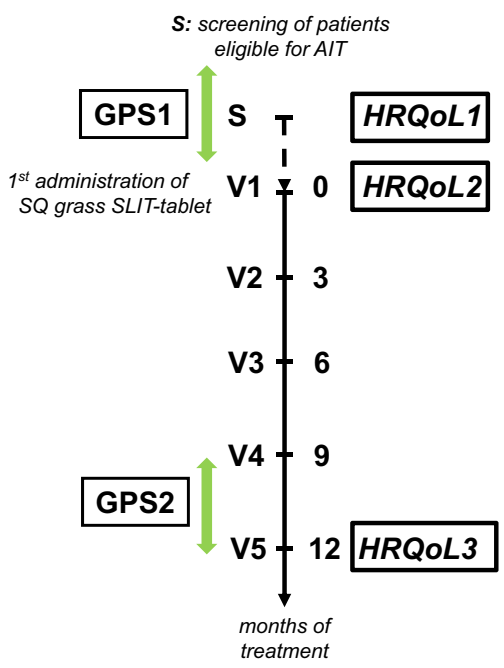

Fig. 1 Study diagram. All patients eligible for AIT were asked to fill in HRQoL instruments for general HRQoL (SF-12) and diseasespecific HRQoL (RQLQ) at the screening visit (S) within the grass pollen season (GPS1) [HRQoL1], after GPS1 (HRQOL2) and in the following grass pollen season (GPS2) [HRQoL3]. Patients who did not start treatment with the $\mathrm{SQ}^{\circledR}$ grass SLIT-tablet and were not treated by another AIT were evaluated as symptomatic medication control group. Patients who returned after GPS1 and were treated with the $\mathrm{SQ}^{\circledR}$ grass SLIT-tablet started the first administration of the $\mathrm{SQ}^{\circledR}$ grass SLIT-tablet at visit 1 (V1) and were followed up at visits every 3 months (V2-V5). AIT allergy immunotherapy, GPS grass pollen season, HRQoL health-related quality of life, SLIT sublingual immunotherapy, $V$ visit

\subsection{Patients}

To be included in the study with the $\mathrm{SQ}^{\circledR}$ grass SLITtablet, patients had to give their consent and be candidates for AIT with the $\mathrm{SQ}^{\circledR}$ grass SLIT-tablet according to normal clinical practice and the indications and contraindications described in the summary of product characteristics (SmPC) [19]. Indications for treatment according to the SmPC are: grass pollen-induced rhinitis and conjunctivitis in adult patients with clinically relevant symptoms and diagnosed with a positive skin-prick test and/or specific immunoglobulin E (IgE) test to grass pollen. Contraindications are: hypersensitivity to any of the excipients (fish-gelatine, mannitol, sodium hydroxide), malignancy or systemic diseases affecting the immune system, e.g. autoimmune diseases, immune complex diseases or immune deficiency diseases, inflammatory conditions in the oral cavity with severe symptoms such as oral lichen planus with ulcerations or severe oral mycosis and patients with uncontrolled or severe asthma [in adults: forced expiratory volume in $1 \mathrm{~s}$ $\left(\mathrm{FEV}_{1}\right)<70 \%$ of predicted value after adequate pharmacologic treatment].

\subsection{Assessments}

HRQoL was self-reported by all patients by means of the 12-Item Short Form Health Survey (SF-12, consisting of 12 items in 8 domains which can be summarised to the two major physical and mental component scores) [2], to assess general HRQoL (score range 0 to $100,100=$ optimal HRQoL) and to assess disease-specific HRQoL by the Rhinoconjunctivitis Quality of Life Questionnaire (RQLQ, assessing the seven domains: activity limitation, sleep problems, non-nose/eye-symptoms, practical problems, nasal symptoms, eye symptoms, emotional function on a scale $0-6$ with $0=$ 'not troubled' and $6=$ 'extremely troubled') [3]. At a screening visit (S) in GPS1 the baseline HRQoL was assessed (HRQoL1) independently from the intended further treatment of the patient by AIT after GPS1. Furthermore, as baseline characteristics of the patients the clinical manifestation of allergy (rhinitis/conjunctivitis/bronchial asthma/atopic dermatitis/other), the medication prescribed (nasal, topical medication, eye drops/oral antihistamines/oral corticosteroids/ $\beta$-agonists/ bronchially applied corticosteroids/other to be specified) and the severity of the allergy were recorded by means of Clinical Global Impression (CGI) on a seven-step scale (not at all ill/borderline ill/mildly ill/moderately ill/markedly ill/severely ill/among the most extremely ill) [20]. The study visits and HRQoL assessments are explained in Fig. 1.

The severity of symptoms in GPS1 (at nose, eyes, lung and skin) and prescription of further symptomatic medication was recorded retrospectively in all patients who returned to the physician's office after GPS1 when patients were asked to assess their off-season HRQoL (HRQoL2). In patients who had agreed to being treated with the $\mathrm{SQ}^{\circledR}$ grass SLIT-tablet, treatment was initiated by the first administration in the physician's office at visit 1 (V1). These patients were followed at visits every 3 months (V2V5) when returning to the physician's office for renewal of prescriptions for the $\mathrm{SQ}^{\circledR}$ grass SLIT-tablet. At V2-V5, adherence, adverse events (AEs) and any discontinuations (including reasons for discontinuation) were recorded by the physician. Serious AEs were notified to the authorities, if applicable according to legal pharmacovigilance procedures.

At the final visit within (V4) or after GPS2 (V5) depending on whether the patient visited the physician's office for renewal of prescriptions of the $\mathrm{SQ}^{\circledR}$ grass SLITtablet, symptoms and use of symptomatic medication during GPS2 were recorded. 


\subsection{Statistical Methods}

For data analysis, descriptive statistical methods and exploratory tests for the comparison of independent subgroups were used ( $t$ test, $U$ test, $\chi^{2}$ test). Patients with evaluable HRQoL data in and/or after GPS1 and in GPS2 in the group treated with the $\mathrm{SQ}^{\circledR}$ grass SLIT-tablet were compared with patients in the symptomatic medication group without AIT. The comparison covers changes of HRQoL in-season (HRQoL3 vs. HRQoL1) and in-season versus off-season (HRQoL3 vs. HRQoL2) [ $t$ test], and improvement rates ( $\chi^{2}$ test). No imputation was performed in case of missing data, but all available data were used to their full extent. AEs were coded according to the current version of the Medical Dictionary for Regulatory Activities (MedDRA). AEs and adverse drug reactions (ADRs) were displayed for patients and on the level of events including multiple occurrences by patient. The principal statistical software used was Statistical Analysis System $\left(\mathrm{SAS}^{\circledR}\right)$, versions 9.3 .

\section{Results}

\subsection{Disposition of Patients}

Overall, data for 576 patients recorded from 155 allergists' offices in Germany were analysed, 364 patients treated with the $\mathrm{SQ}^{\circledR}$ grass SLIT-tablet could be analysed for safety and 211 grass pollen-allergic patients as controls (Fig. 2). HRQoL data were available for 320 patients treated with the SQ ${ }^{\circledR}$ grass SLIT-tablet and 192 patients in the control group. Symptomatic medication prescribed at baseline (in GPS1) was in the SLIT-tablet group (multiple ratings): nasal, topical medication, eye drops 226 (70.6\%) patients, oral antihistamines $248(77.5 \%)$, oral corticosteroids $42(13.1 \%), \beta$-agonists $12(3.8 \%)$, bronchially applied corticosteroids $42(13.1 \%)$, others 10 (3.1\%) and in the control group: nasal, topical medication, eye drops $124(64.6 \%)$ patients, oral antihistamines $248(69.8 \%)$, oral corticosteroids 42 (10.9\%), $\beta$-agonists 12 (4.2\%), bronchially applied corticosteroids $20(10.4 \%)$, others 1 $(0.5 \%)$. Patients who were treated with the $\mathrm{SQ}^{\circledR}$ grass SLIT-tablet, but did not participate in the study $(N=30)$, patients treated by another AIT than the SQ ${ }^{\circledR}$ grass SLITtablet $(N=27)$ and patients who did not return $(N=30)$ were excluded from the control group to obtain the symptomatic medication control group used for comparison of the HRQoL data between the $\mathrm{SQ}^{\circledR}$ grass SLITtablet group and the symptomatic control group without AIT.

The baseline characteristics of all patients who provided HRQoL data and were eligible for a comparison of GPS2 and GPS1 (HRQoL3 vs. HRQoL1), are shown in Table 1. No larger differences between the $\mathrm{SQ}^{\circledR}$ grass SLIT-tablet group and the symptomatic medication control group were
Fig. 2 Flow diagram. AIT allergy immunotherapy, $H R Q o L$ health-related quality of life, SLIT sublingual immunotherapy

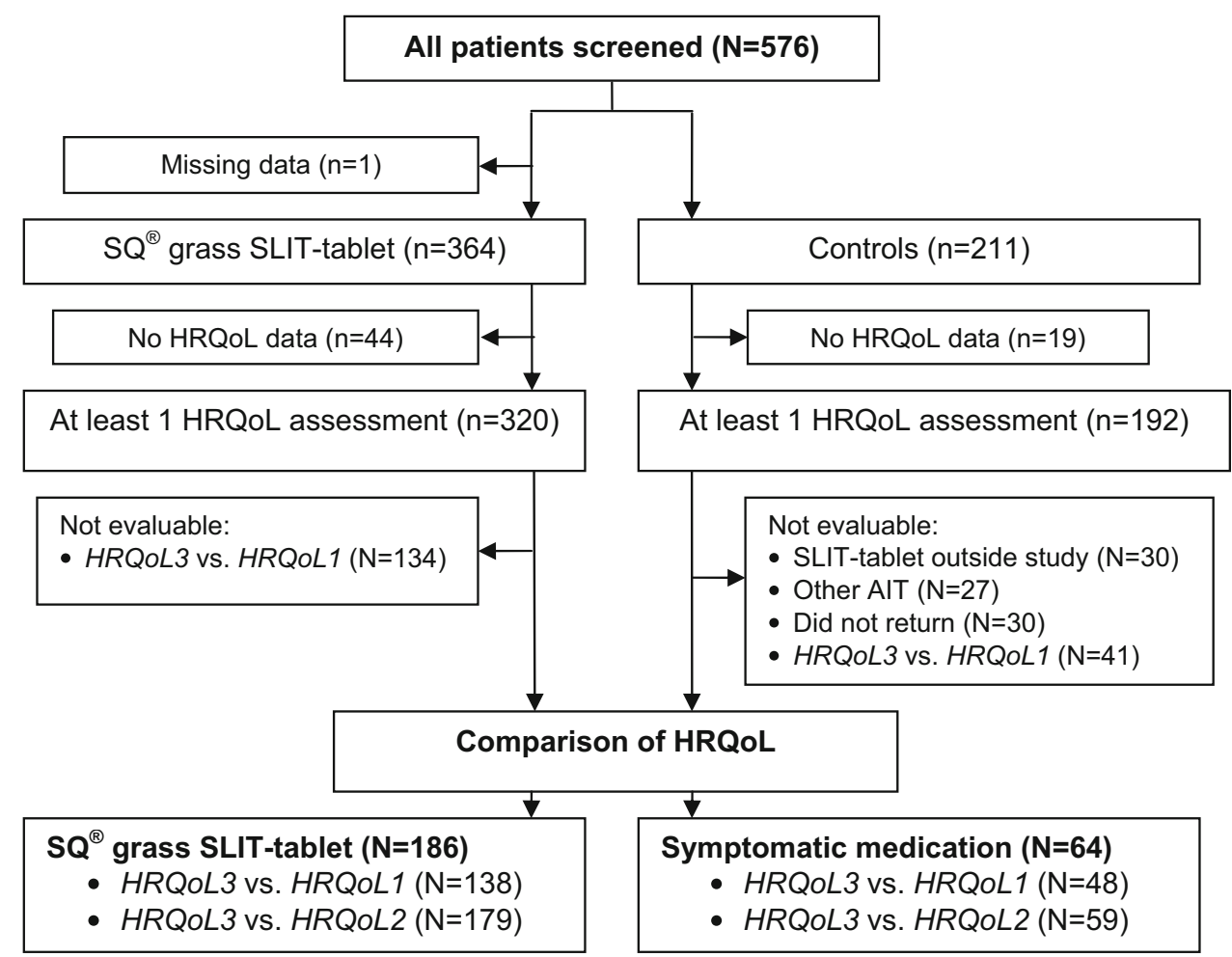


Table 1 Baseline characteristics of patients with evaluable health-related quality of life (HRQoL) data

\begin{tabular}{|c|c|c|}
\hline Characteristic & $\mathrm{SQ}^{\circledR}$ grass SLIT-tablet group & $\overline{\text { Symptomatic medication control group }}$ \\
\hline Number of patients & 186 & 64 \\
\hline Median age (range), years & $32.0(12-68)$ & $35.5(16-63)$ \\
\hline Patients $<18$ years, $N(\%)$ & $9(4.8)$ & $2(3.1)$ \\
\hline \multicolumn{3}{|l|}{$\operatorname{Sex}, N(\%)$} \\
\hline Men & $91(48.9)$ & $29(45.3)$ \\
\hline Women & $95(51.1)$ & $35(54.7)$ \\
\hline Bronchial asthma, $N(\%)$ & $54(29.0)$ & $12(18.8)$ \\
\hline Severity of allergy: Clinical Global Impression (CGI), mean (SD) & $4.70(0.67)$ & $4.11(0.68)$ \\
\hline \multicolumn{3}{|l|}{ CGI, $N(\%)$} \\
\hline Not at all ill & - & - \\
\hline Borderline ill & $1(0.5)$ & $1(1.6)$ \\
\hline Mildly ill & $4(2.2)$ & $7(11.3)$ \\
\hline Moderately ill & $58(31.4)$ & $39(62.9)$ \\
\hline Markedly ill & $109(58.9)$ & $14(22.6)$ \\
\hline Severely ill & $12(6.5)$ & $1(1.6)$ \\
\hline Extremely ill & $1(0.5)$ & - \\
\hline \multicolumn{3}{|l|}{ Attitude towards immunotherapy with $\mathrm{SQ}^{\circledR}$ grass SLIT-tablet, $N(\%)$} \\
\hline Interested in immunotherapy with the $\mathrm{SQ}^{\circledR}$ grass SLIT-tablet & $181(97.3)$ & $16(25.0)$ \\
\hline Sceptical about immunotherapy with the SQ ${ }^{\circledR}$ grass SLIT-tablet & $5(2.7)$ & $26(40.6)$ \\
\hline Refused immunotherapy with the $\mathrm{SQ}^{\circledR}$ grass SLIT-tablet & - & $22(34.4)$ \\
\hline
\end{tabular}

SLIT sublingual immunotherapy

observed with respect to age and gender. The frequency of bronchial asthma was higher in the $\mathrm{SQ}^{\circledR}$ grass SLIT-tablet group, but not statistically significant. However, patients in the $\mathrm{SQ}^{\circledR}$ grass SLIT-tablet group had a higher severity of allergy according to CGI with more patients assessed as 'markedly ill' as compared with the symptomatic medication control group. Accordingly, SF-12 and RQLQ scores of HRQoL1 (in GPS1) and HRQoL2 (after GPS1) were significantly higher in the $\mathrm{SQ}^{\circledR}$ grass SLIT-tablet group than in the symptomatic medication control group. For patients in the $\mathrm{SQ}^{\circledR}$ grass SLIT-tablet group, a different attitude towards AIT (more patients were interested in AIT with the $\mathrm{SQ}^{\circledR}$ grass SLIT-tablet and fewer patients were sceptical or refused AIT with the $\mathrm{SQ}^{\circledR}$ grass SLIT-tablet) was recorded as compared to the symptomatic medication control group at the screening visit (S) in GPS1.

For 134 patients treated with the SQ ${ }^{\circledR}$ grass SLIT-tablet and 41 allergic patients in the control group, no HRQoL data were available for comparison of HRQoL in GPS1 and GPS2 (HRQoL3 vs. HRQoL1). HRQoL data were available for analysis in GPS2 versus GPS1 for 138 patients in the $\mathrm{SQ}^{\circledR}$ grass SLIT-tablet group and 48 patients in the symptomatic medication control group, and HRQoL data for analysis in GPS2 versus outside GPS1 (HRQoL3 vs. HRQoL2) for 179 patients in the $\mathrm{SQ}^{\circledR}$ grass SLIT-tablet group and 59 patients in the symptomatic medication control group (Table 2).

\subsection{General HRQoL (SF-12)}

The overall baseline results from SF-12 overall score and the results for the physical and mental component scores in GPS1 (HRQoL1) were lower in the SQ ${ }^{\circledR}$ grass SLIT-tablet group than in the symptomatic medication control group (Table 2) corresponding to the higher baseline severity of the allergic disease assessed according to the CGI-scale in the $\mathrm{SQ}^{\circledR}$ grass SLIT-tablet group (Table 1).

In the SQ ${ }^{\circledR}$ grass SLIT-tablet group, the overall SF-12 results as well as the physical and mental component scores markedly increased in the first GPS with treatment by the $\mathrm{SQ}^{\circledR}$ grass SLIT-tablet (GPS2) compared with GPS1 at baseline (HRQoL3 vs. HRQoL1) with largest improvement for the physical component score. In the symptomatic medication control group, SF-12 scores slightly decreased. The differences between the mean score changes were statistically significant ( $p<0.0001, t$ test). Changes in SF12 scores between HRQoL3 (GPS2) and HRQoL1 at baseline (GPS1) after 9 to 12 months of treatment are presented in Fig. 3. Mean overall SF-12 scores and physical and mental component scores decreased only slightly in GPS2 (HRQoL3) as compared with scores outside GPS2 (HRQoL2) in the $\mathrm{SQ}^{\circledR}$ grass SLIT-tablet group (mean \pm SD)—overall: $\quad(-1.6 \pm 15.3)$; physical: $\quad(-$ $2.3 \pm 18.7)$; mental: $(-1.2 \pm 15.9)$, but decreased markedly in the symptomatic medication control group- 
Table 2 Mean health-related quality of life (HRQoL) scores ( $\pm \mathrm{SD}$ ) in patients with assessments at HRQoL1 (in GPS1), HRQoL2 (after GPS1) and HRQoL3 (in GPS2)

\begin{tabular}{|c|c|c|c|c|c|c|c|c|}
\hline & \multicolumn{4}{|c|}{$\begin{array}{l}\text { Mean HRQoL scores }( \pm \mathrm{SD}) \text { in patients with assessments } \\
\text { HRQoL3 and HRQoL1 }\end{array}$} & \multicolumn{4}{|c|}{$\begin{array}{l}\text { Mean HRQoL scores ( } \pm \text { SD) in patients with } \\
\text { assessments HRQoL2 and HRQoL3 }\end{array}$} \\
\hline & \multicolumn{2}{|c|}{$\begin{array}{l}\mathrm{SQ}^{\circledR} \text { grass SLIT-tablet group } \\
(N=138)\end{array}$} & \multicolumn{2}{|c|}{$\begin{array}{l}\text { Symptomatic medication } \\
\text { control group }(N=48)\end{array}$} & \multicolumn{2}{|c|}{$\begin{array}{l}\mathrm{SQ}^{\circledR} \text { grass SLIT-tablet } \\
\text { group }(N=179)\end{array}$} & \multicolumn{2}{|c|}{$\begin{array}{l}\text { Symptomatic medication } \\
\text { control group }(N=59)\end{array}$} \\
\hline & $\begin{array}{l}\text { HRQoL1 } \\
\text { (baseline) }\end{array}$ & $\begin{array}{l}H R Q o L 3 \\
\text { (in GPS2) }\end{array}$ & $\begin{array}{l}\text { HRQoL1 } \\
\text { (baseline) }\end{array}$ & $\begin{array}{l}H R Q o L 3 \\
\text { (in GPS2) }\end{array}$ & $\begin{array}{l}\text { HRQoL2 } \\
\text { (after GPS1) }\end{array}$ & $\begin{array}{l}H R Q o L 3 \\
\text { (in GPS2) }\end{array}$ & $\begin{array}{l}\text { HRQoL2 } \\
\text { (after GPS1) }\end{array}$ & $\begin{array}{l}H R Q o L 3 \\
\text { (in GPS2) }\end{array}$ \\
\hline \multicolumn{9}{|c|}{ SF-12 (score range $0-100)^{\mathrm{a}}$} \\
\hline Overall score & $64.8(17.7)$ & $76.1(13.9)$ & $71.4(16.6)$ & $68.0(19.5)$ & $77.2(14.0)^{\mathbf{c}}$ & $75.6(15.2)$ & $82.2(11.5)^{\mathbf{d}}$ & $72.3(16.9)$ \\
\hline $\begin{array}{l}\text { Physical component } \\
\text { score }\end{array}$ & $65.5(21.6)$ & $78.5(15.8)$ & $72.3(19.9)$ & $69.5(20.3)$ & $80.5(16.3)$ & $78.2(16.7)$ & $85.4(12.4)$ & $73.1(18.5)$ \\
\hline $\begin{array}{l}\text { Mental component } \\
\text { score }\end{array}$ & $64.3(17.7)$ & $74.6(15.3)$ & $70.8(17.5)$ & $67.0(20.6)$ & $75.0(15.3)$ & $73.8(16.3)$ & $80.1(13.1)$ & $71.9(17.9)$ \\
\hline \multicolumn{9}{|c|}{ RQLQ (score range $0-6)^{\mathrm{b}}$} \\
\hline Overall score & $2.62(0.90)$ & $1.31(0.96)$ & $2.18(0.93)$ & $2.28(1.03)$ & $1.13(1.10)$ & $1.36(1.05)$ & $0.74(0.85)$ & $1.98(1.08)$ \\
\hline Activity limitation & $2.74(1.09)$ & $1.47(1.15)$ & $2.28(1.19)$ & $2.48(1.34)$ & $1.17(1.27)$ & $1.49(1.23)$ & $0.85(1.18)$ & $2.22(1.39)$ \\
\hline Sleep problems & $2.26(1.27)$ & $1.19(1.01)$ & $1.95(1.44)$ & $2.08(1.30)$ & $1.04(1.13)$ & $1.22(1.13)$ & $0.69(0.83)$ & $1.75(1.33)$ \\
\hline $\begin{array}{l}\text { Non-nose/eye } \\
\text { symptoms }\end{array}$ & $2.21(1.14)$ & $1.14(1.01)$ & $1.92(1.07)$ & $2.04(1.13)$ & $1.07(1.09)$ & $1.20(1.08)$ & $0.70(0.86)$ & $1.73(1.09)$ \\
\hline Practical problems & $3.41(1.30)$ & $1.68(1.44)$ & $3.02(1.33)$ & $2.88(1.42)$ & $1.41(1.51)$ & $1.77(1.51)$ & $0.94(1.29)$ & 2.57 (1.46) \\
\hline Nasal symptoms & $3.46(1.21)$ & $1.70(1.30)$ & 2.74 (1.16) & $2.90(1.31)$ & $1.42(1.47)$ & $1.76(1.34)$ & $0.94(1.15)$ & $2.63(1.37)$ \\
\hline Eye symptoms & $2.53(1.28)$ & $1.14(1.08)$ & $2.06(1.25)$ & $2.12(1.10)$ & $0.91(1.23)$ & $1.22(1.17)$ & $0.53(0.85)$ & $1.87(1.13)$ \\
\hline Emotional function & $2.20(1.10)$ & $1.05(1.04)$ & $1.68(1.11)$ & $1.81(1.14)$ & $1.02(1.15)$ & $1.08(1.09)$ & $0.64(0.88)$ & $1.48(1.12)$ \\
\hline
\end{tabular}

GPS grass pollen season, $R Q L Q$ Rhinoconjunctivitis Quality of Life Questionnaire, SF-12 12-Item Short Form Health Survey, SLIT sublingual immunotherapy

a SF-12: optimal HRQoL (100)

b RQLQ: optimal HRQoL (0)

${ }^{\mathrm{c}} N=178$

${ }^{\mathrm{d}} N=58$

overall: $(-10.4 \pm 14.1)$; physical: $(-12.3 \pm 18.5)$; mental: $(-8.2 \pm 13.9)$. The differences between the mean score changes of the two groups were statistically significant $(p<0.01, t$ test).

In the SQ ${ }^{\circledR}$ grass SLIT-tablet group, 98 of 138 patients (71.0\%) showed improvements of their general intra-seasonal HRQoL according to the overall SF-12 score whereas 17 of $48(35.4 \%)$ patients had an improvement in the symptomatic medication control group $(p<0.0001$, $\chi^{2}$ test).

\subsection{Disease-Specific HRQoL (RQLQ)}

The baseline RQLQ scores (overall score as well as scores of the seven individual domains) in GPS1 (HRQoL1) were higher in the $\mathrm{SQ}^{\circledR}$ grass SLIT-tablet group compared with the group of patients receiving symptomatic treatment without AIT (Table 2). This was in line with the pattern observed for the SF-12 scores. A marked improvement in the overall RQLQ score $(-1.31 \pm 0.96)$ between the baseline scores in GPS1 (HRQoL1) and the scores in GPS2
(HRQoL3) was observed for the group of patients treated with the $\mathrm{SQ}^{\circledR}$ grass SLIT-tablet. Largest improvements from baseline in the $\mathrm{SQ}^{\circledR}$ grass SLIT-tablet group were observed in the domains: nose symptoms $(-1.75 \pm 1.44)$, practical problems $(-1.72 \pm 1.53)$ and eye symptoms ($1.39 \pm 1.37)$. In the symptomatic medication control group a slight increase of the overall score $(+0.10 \pm 0.74)$ was observed corresponding to a slight deterioration of diseasespecific HRQoL (Fig. 4). The differences in the mean score changes between the two groups were statistically significant $(p<0.0001, t$ test $)$. In the $\mathrm{SQ}^{\circledR}$ grass SLIT-tablet group, 121 of $138(87.7 \%)$ patients showed improvements in their disease-specific intra-seasonal HRQoL versus 19 of $48(39.6 \%)$ patients in the symptomatic medication control group ( $p<0.0001, \chi^{2}$ test).

When comparing the RQLQ scores in GPS2 (HRQoL3) with the scores observed outside GPS1 (HRQoL2) in patients treated with the $\mathrm{SQ}^{\circledR}$ grass SLIT-tablet, scores slightly increased $(0.22 \pm 1.29$ for the overall score) but markedly increased in the symptomatic medication control group $(1.24 \pm 1.30)$. 

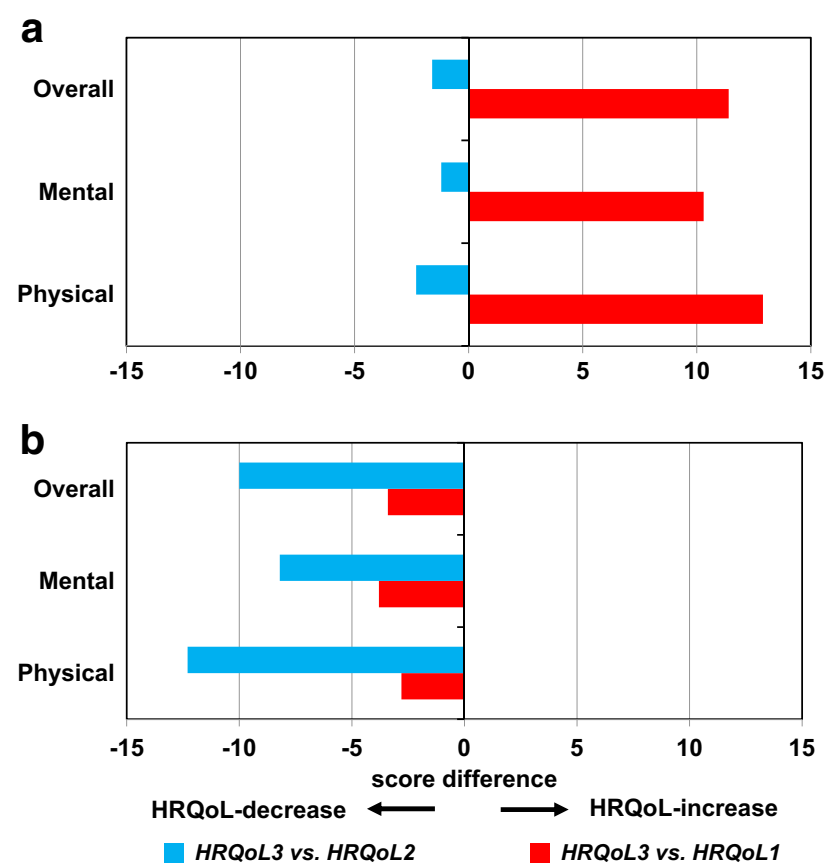

Fig. 3 Changes in SF-12-scores for the SF-12 overall score and the physical and mental component scores in the $\mathrm{SQ}^{\circledR}$ grass SLIT-tablet group (a) and the symptomatic medication control group (b) between HRQoL-assessments in grass pollen season 2 (GPS2) after 9 to 12 months of treatment and in baseline grass pollen season 1 (GPS1), (HRQoL3 vs. HRQoL1), and between HRQoL-assessments in grass pollen season 2 (GPS2) and after GPS1 (outside the grass pollen season), (HRQoL3 vs. HRQoL2). Differences in changes between the $\mathrm{SQ}^{\circledR}$ grass SLIT-tablet group and the symptomatic medication control group were statistically significant (overall score: $p=0.0003$, mental component score: $p=0.0028$, physical component score: $p=0.0005)$. HRQoL health-related quality of life, $S F-12$ 12-Item Short Form Health Survey, SLIT sublingual immunotherapy

\subsection{Assessment of Treatment Effect with the $\mathrm{SQ}^{\circledR}$ Grass SLIT-Tablet}

Median duration of treatment with the $\mathrm{SQ}^{\circledR}$ grass SLITtablet was 11.5 (mean $10.89 \pm 3.44 \mathrm{SD}$ ) months. The proportion of patients treated with the $\mathrm{SQ}^{\circledR}$ grass SLITtablet with improved symptoms or patients who became free of symptoms in GPS2 versus GPS1 (baseline) was $78.5 \%$ for nose symptoms $(12.1 \%$ became free of nose symptoms), $73.6 \%$ for eye symptoms ( $28.1 \%$ became free of eye symptoms), $75.5 \%$ for bronchial symptoms (49.7\% became free of bronchial symptoms) and $52.1 \%$ for skin symptoms ( $40.8 \%$ became free of skin symptoms). The proportion of patients who used additional symptomatic medication in the $\mathrm{SQ}^{\circledR}$ grass SLIT-tablet group decreased from $96.5 \%$ in GPS1 (baseline) to $52.1 \%$ in GPS2.

\subsection{Adherence and Tolerability}

Between $77.2 \%$ out of 189 patients with data for the fourth prescription interval and $80.1 \%$ of patients out of 331 patients (two missing values) with data for the first assessed prescription interval were assessed to have taken the $\mathrm{SQ}^{\circledR}$ grass SLIT-tablet regularly (one tablet per day) during the study. The question 'did the patient take the $\mathrm{SQ}^{\circledR}$ grass SLIT-tablet regularly in all documented prescription intervals' was answered 'yes' in $63.2 \%$ out of 331 patients (two missing values) with initiation of treatment with the $\mathrm{SQ}^{\circledR}$ grass SLIT-tablet who had been included in the study and had at least one follow-up visit. Treatment with the $\mathrm{SQ}^{\circledR}$ grass SLIT-tablet was continued after the last visit of the study in 230 out of $364(63.2 \%)$ patients who initially started treatment.

AEs were reported in $17.9 \%$ of patients treated with the $\mathrm{SQ}^{\circledR}$ grass SLIT-tablet. The majority of these events were judged to be related to the administration of the $\mathrm{SQ}^{\circledR}$ grass SLIT-tablet and occurred at the first administration. None of the AEs were serious. Treatment with the $\mathrm{SQ}^{\circledR}$ grass SLIT-tablet was discontinued due to AEs in 18 patientsin the majority of the patients due to local reactions at the application site in the mouth, and cough, respiratory distress, exanthema and urticaria (each in a single case); 10 patients were medically treated, primarily by antihistamines (allergic rhinitis/conjunctivitis, local reactions at the application site, exanthema/itch, anxiety state) and by an aerosol due to cough and by a beta-blocker due to hypertension. The most frequently reported AEs were local reactions at the administration site in the mouth (oral pruritus, paraesthesia oral, oedema mouth and swollen lip/tongue).

\section{Discussion}

HRQoL self-assessed by patients is very important as an outcome parameter for measurement of patients' individually perceived benefit and for analysis of cost-effectiveness of a therapeutic intervention [1]. Both disease-specific and general HRQoL instruments have been validated in different languages and published [2,3]. Improvements of the disease-specific HRQoL are especially important for long-term treatments like AIT.

Our study has shown that patients routinely treated in the allergist's office with the SQ ${ }^{\circledR}$ grass SLIT-tablet perceive remarkable improvements in general and diseasespecific HRQoL after approximately 12 months of treatment as compared to baseline. 
Fig. 4 Changes in RQLQ scores for individual domains and overall scores in the $\mathrm{SQ}^{\circledR}$ grass SLIT-tablet group (a) and the symptomatic medication control group (b) between HRQoL assessments in grass pollen season 2 (GPS2) after 9 to 12 months of treatment and in baseline grass pollen season 1 (GPS1), (HRQoL3 vs.

HRQoL1), and between HRQoL-assessments in GPS2 and after GPS1 (outside the grass pollen season), (HRQoL3 vs. HRQoL2). Differences in changes between the two groups were statistically significant for the overall scores and the scores for all seven RQLQ-domains $(p<0.0001)$. HRQoL healthrelated quality of life, $R Q L Q$ Rhinoconjunctivitis Quality of Life Questionnaire, SLIT sublingual immunotherapy a
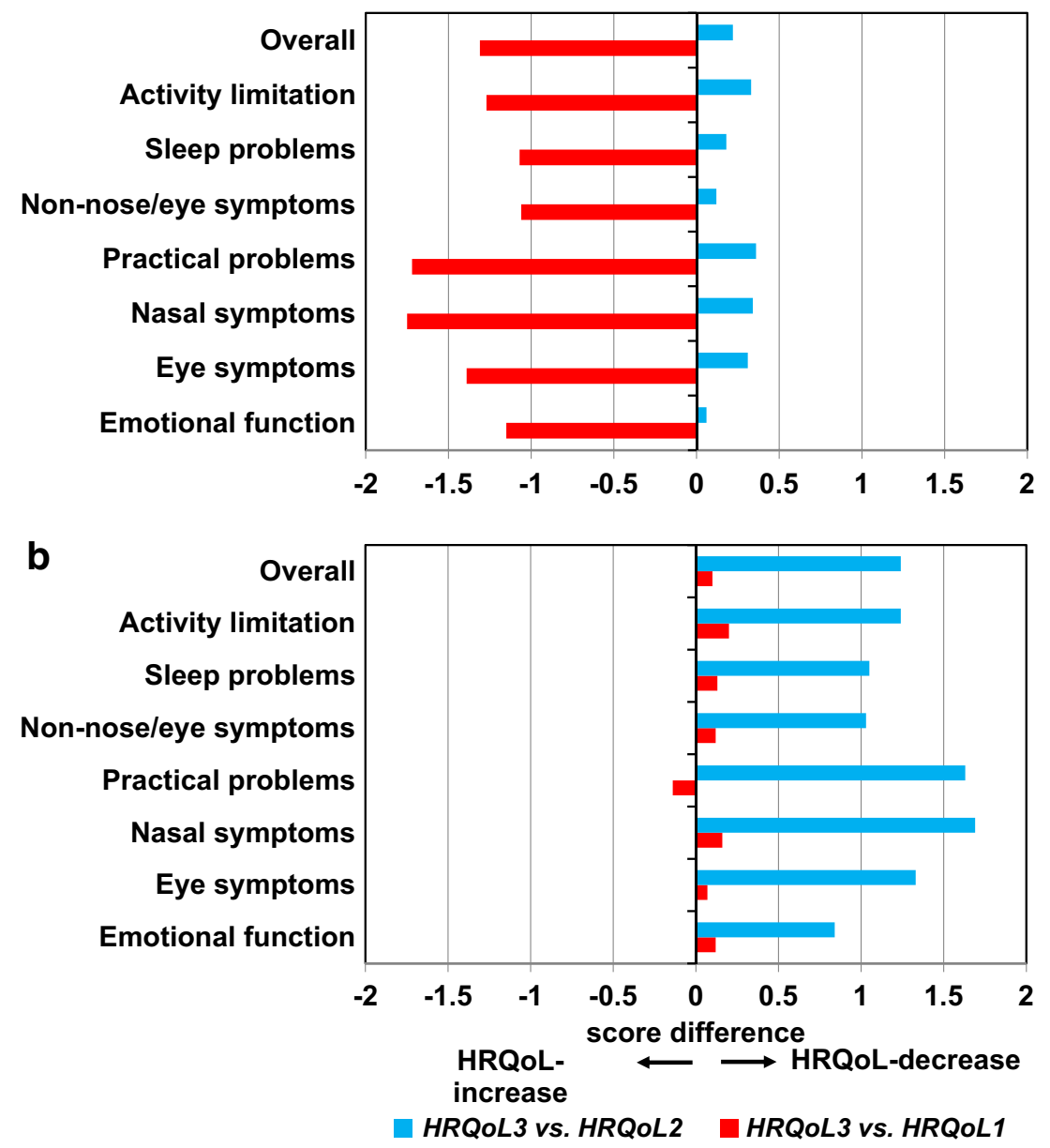

All improvements in the intra-seasonal disease-specific HRQoL for the SQ ${ }^{\circledR}$ grass SLIT-tablet group were clearly above the threshold of 0.5 for a clinically important improvement previously defined by Juniper [21, 22].

No improvement in the HRQoL was observed in patients treated only with unspecific commonly used symptomatic medication such as antihistamines, corticosteroid nasal sprays and/or eye drops. The HRQoL for the allergic patients treated with symptomatic medication did not change, but tended to deteriorate as was to be expected for patients with unspecific treatment of allergy. The differences in HRQoL scores between AIT with the $\mathrm{SQ}^{\circledR}$ grass SLIT-tablet and the unspecific treatment by symptomatic medication were highly significant. It has to be taken into consideration that the allocation of the patients to the $\mathrm{SQ}^{\circledR}$ grass SLIT-tablet group or to the symptomatic medication control group was performed according to reallife procedures (i.e. as an agreement between physician and patient) and not by randomisation as in a RCT. Accordingly, the $\mathrm{SQ}^{\circledR}$ grass SLIT-tablet group and symptomatic medication control group were only comparable with respect to age and gender, but different for frequency of asthma and with respect to a higher severity of allergy according to the CGI scale and a different attitude towards AIT with the $\mathrm{SQ}^{\circledR}$ grass SLIT-tablet and impairment of HRQoL at baseline.

Nevertheless, in our study improvements in HRQoL were observed that confirm the results from previously conducted RCTs with the SQ ${ }^{\circledR}$ grass SLIT-tablet [12, 14, $18]$ and indicate the potential for significant improvements in HRQoL after treatment with the $\mathrm{SQ}^{\circledR}$ grass SLIT-tablet in real-life.

Limitations of our study are those of a prospective, open-label, uncontrolled observational study in the real-life setting. In order to minimise a potential investigator bias, sites distributed all over Germany were involved. For reduction of a potential selection bias physicians were asked to include patients in a consecutive order according to the consent of the patients to be included in the study. A source of potential bias in comparisons of the HRQoL scores between GPS2 and GPS1 is the number of pollen grains the individual patient has been exposed to and the natural variability of the grass-pollen load in Germany in the two GPS compared in our study potentially inducing an 
increase in perceived HRQoL by patients in case of a lower pollen exposure in GPS2 after about one year of treatment compared with baseline GPS1.

\section{Conclusion}

In conclusion, routine treatment with the $\mathrm{SQ}^{\circledR}$ grass SLITtablet resulted in clear improvements in disease-specific and general HRQoL as compared to unspecific treatment with symptomatic medication only.

Acknowledgments We would like to thank all physicians who participated in the study.

\section{Compliance with Ethical Standards}

Funding ALK sponsored this study and was involved in trial design, data collection, analysis and interpretation.

Conflicts of interest A. Horn and $\mathrm{H}$. Zeuner received remuneration from ALK for the documentation of patient data from their practice. They previously participated as investigators in clinical trials sponsored by ALK. A Horn received remuneration from ALK for educational presentations and is advisory board member for ALK. J Schnitker was funded by ALK as Clinical Research Organisation (CRO) in the study. H Wolf and E Wüstenberg are employees of ALK. The investigators received remuneration from ALK for the documentation of treatment of their patients. IAS GmbH received as CRO remuneration from ALK for its services in biometrical planning, data management and statistical analysis of the study.

Ethical approval All procedures in this study were in accordance with the 1964 Helsinki declaration (and its amendments), since only data on treatment as part of the routine medical practice were recorded the study was not subject to approval by an independent ethics committee.

Informed consent Patients were asked for their consent to participate in the study. Written informed consent was not required because only data as part of the routine medical practice were recorded.

Open Access This article is distributed under the terms of the Creative Commons Attribution-NonCommercial 4.0 International License (http://creativecommons.org/licenses/by-nc/4.0/), which permits any noncommercial use, distribution, and reproduction in any medium, provided you give appropriate credit to the original author(s) and the source, provide a link to the Creative Commons license, and indicate if changes were made.

\section{References}

1. Bousquet J, Khaltaev N, Cruz AA, Denburg J, Fokkens WJ, Togias A, et al. Allergic Rhinitis and its Impact on Asthma (ARIA) 2008 update (in collaboration with the World Health Organization, GA(2)LEN and AllerGen). Allergy. 2008;63(Suppl 86):8-160.

2. Ware J Jr, Kosinski M, Keller SD. A 12-Item Short-Form Health Survey: construction of scales and preliminary tests of reliability and validity. Med Care. 1996;34(3):220-33.
3. Juniper EF, Guyatt GH. Development and testing of a new measure of health status for clinical trials in rhinoconjunctivitis. Clin Exp Allergy. 1991;21(1):77-83.

4. Malling H-J, Lund L, Ipsen H, Poulsen LK. Safety and immunological changes during specific sublingual immunotherapy with SQ standardized grass allergen tablets. J Investig Allergol Clin Immunol. 2006;16:162-8.

5. Kleine-Tebbe J, Ribel M, Herold DA. Safety of a SQ-standardised grass allergen tablet for sublingual immunotherapy: a randomized, placebo-controlled trial. Allergy. 2006;61:181-4.

6. Calderon M, Essendrop M. Specific immunotherapy with high dose SQ standardised grass allergen tablets was safe and well tolerated. J Investig Allergol Clin Immunol. 2006;16:338-44.

7. Ibañez MD, Kaiser F, Knecht R, Armentia A, Schöpfer H, Tholstrup B, Bufe A. Safety of specific sublingual immunotherapy with SQ standardized grass allergen tablets in children. Pediatr Allergy Immunol. 2007;18:516-22.

8. Durham SR, Yang WH, Pedersen MR, Johansen N, Rak S. Sublingual immunotherapy with once-daily grass allergen tablets: a randomized controlled trial in seasonal allergic rhinoconjunctivitis. J Allergy Clin Immunol. 2006;117:802-9.

9. Dahl R, Kapp A, Colombo G, de Monchy J, Rak S, Emminger W, Fernández Rivas M, Ribel M, Durham SR. Efficacy and safety of sublingual immunotherapy with grass allergen tablet for seasonal allergic rhinoconjunctivitis. J Allergy Clin Immunol. 2006;118:434-40.

10. Dahl R, Stender A, Rak S. Specific immunotherapy with SQ standardized grass allergen tablets in asthmatics with rhinoconjunctivitis. Allergy. 2006;61:185-90.

11. Bufe A, Eberle P, Franke-Beckmann E, Funck J, Kimmig M, Klimek L, Knecht R, Stephan V, Tholstrup B, Weißhaar C, Kaiser F. Safety and efficacy in children of an SQ-standardized grass allergen tablet for sublingual immunotherapy. J Allergy Clin Immunol. 2009;23:167-73.

12. Dahl R, Kapp A, Colombo G, De Monchy JG, Rak S, Emminger W, Riis B, Grønager PM, Durham SR. Sublingual grass allergen tablet immunotherapy provides sustained clinical benefit with progressive immunologic changes over 2 years. J Allergy Clin Immunol. 2008;121:512-8.

13. Durham SR, Emminger W, Kapp A, Colombo G, de Monchy JGR, Rak S, Scadding GK, Andersen JS, Riis B, Dahl R. Longterm clinical efficacy in grass pollen-induced rhinoconjunctivitis after treatment with SQ-standardized grass allergy immunotherapy tablet. J Allergy Clin Immunol. 2010;125:131-8.

14. Durham SR, Emminger W, Kapp A, de Monchy JGR, Rak S, Scadding GK, Wurtzen PA, Andersen JS, Tholstrup B, Riis B, Dahl R. SQ-standardized sublingual grass immunotherapy: Confirmation of disease modification 2 years after 3 years of treatment in a randomized trial. J Allergy Clin Immunol. 2012;129:717-25.

15. Blaiss M, Maloney J, Nolte H, Gawchik S, Yao R, Skoner DP. Safety of timothy grass allergy immunotherapy tablets in north American children and adolescents. J Allergy Clin Immunol. 2011;127:64-7.

16. Nelson HS, Nolte H, Creticos P, Maloney J, Wu J, Bernstein DI. Efficacy and safety of timothy grass allergy immunotherapy tablet in north american adults. J Allergy Clin Immunol. 2011;127:72-80.

17. Maloney J, Bernstein DI, Nelson H, Creticos P, Hébert J, Noonan M, Skoner D, Zhou Y, Kaur A, Nolte H. Efficacy and safety of grass sublingual immunotherapy tablet, MK-7243: a large randomized controlled trial. Ann Allergy Asthma Immunol. 2014;112:146-53.

18. Frølund L, Durham SR, Calderon M, Emminger W, Andersen JS, Rask P, Dahl R. Sustained effect of SQ-standardized grass allergy 
immunotherapy tablet on rhinoconjunctivitis quality of life. Allergy. 2010;65:753-7.

19. GRAZAX $^{\circledR}(75,000$ SQ-T oral lyophilisate) [summary of product characteristics] (2006). Wedel, Germany: ALK; dated Oct 2006.

20. Guy W. Clinical Global Impression. ECDEU assessment manual for psychopharmacology, revised. Rockville: National Institute of Mental Health; 1976.

21. Juniper EF. Quality of life questionnaires: does statistically significant $=$ clinically important $? \mathrm{~J}$ Allergy Clin Immunol. 1998;102(1):16-7.

22. Juniper EF, Guyatt GH, Griffith LE, Ferrie PJ. Interpretation of rhinoconjunctivitis quality of life questionnaire data. J Allergy Clin Immunol. 1996;98(4):843-5.
23. Horn A, Zeuner H, Wolf H, Schnitker J, Wüstenberg E. Quality of life during routine treatment with the SQ-standardised grass allergy immunotherapy tablet. Allergy. 2010;65 (Suppl 92):579-80 (Poster presentation at the 29th EAACI-Congress, 05 to 09 June 2010, London, UK).

24. Wolf H, Horn A, Zeuner H, Schnitker J, Wüstenberg E. Lebensqualität während der Routine-Behandlung mit der SQ-standardisierten Gräser-Allergie-Immuntherapietablette. Allergo J. 2010;19:S49 (Poster presentation at the 5th German Allergy Congress, 08 to 11 September 2010 Hannover, Germany). 